\title{
Editorial PIAM April 2020
}

\author{
Eujin Pei ${ }^{1}$
}

Published online: 28 April 2020

(c) Springer Nature Switzerland AG 2020

The second issue for 2020 (Volume 5 Issue 2) covers a wide range of interesting topics from using Additive Manufacturing for medical applications, structural optimization of medical implants and producing solid forms of oral dosage. Other papers in this issue include build process planning, diameter dependence on temperature and velocity for material extrusion, electrically conductive graphite-polymer composites, wire-arc processes, welding of dissimilar materials, layered manufacturing of bimetallic molds, quality and productivity for powder bed fusion, cellular lattice structures and the effect of post-processing on surfaces.

We have taken steps to reduce the time it takes to make decisions for manuscripts that we receive. For example, we took an average of 73 days in 2019 and we have reduced this to 41 days for the majority of manuscripts to be processed. The number of pages for our issues has also increased with high quality content, for example from publishing just 70 pages in Volume 4 Issue 1, to 162 pages in Volume 4 Issue 4. Our full-text article requests have also grown proportionately, from just 8950 requests in 2016 to an impressive 53,200 requests in 2019 . As our journal continues to establish itself in the research community, I take this opportunity to thank our contributors, reviewers and editorial board members. We are also keen to work closely with you, by listening to your comments, feedback or to be a reviewer with us. Our contact details are available on our website via: https://www.springer.com/journal/40964/contact-the-journal

Closer to home, our world has dramatically changed with the COVID-19 situation. It was unexpected and manufacturers continue to keep up with the demand for medical supplies and personal protective equipment (PPE). Examples of products being made by Additive Manufacturing include respirators, nasal swabs and ventilator parts. At the same time, the maker movement with Additive Manufacturing facilities using desktop 3D printers has produced parts for face shields. A much bigger challenge is to use Additive Manufacturing to produce products that have safety implications such as for ventilator splitters, venturi valves and flow restriction devices and ensuring that these parts fully conform to manufacturing and user requirements. This could be where the need for Additive Manufacturing standards becomes ever more important.

The Progress in Additive Manufacturing journal is keen to receive manuscripts that document findings arising from COVID-19, so that the research community, scientists, researchers, academics and end users can benefit from the new knowledge being generated. We would like to help authors publish their research findings in a timely manner and without unnecessary delays. The expedited review can be offered on request, particularly for research articles that demonstrate high quality, novel and important results. We will offer a fast-track process that will reduce the amount of time allocated for peer review, but also ensuring that the review process is still stringent and according to academic publishing guidelines.

I take this opportunity to wish all readers, authors, reviewers and editorial board members a safe 2020 .

\section{Eujin Pei}

Progress in Additive Manufacturing Journal April 2020

Publisher's Note Springer Nature remains neutral with regard tojurisdictional claims in published maps and institutional affiliations.
Eujin Pei

eujinpei1@gmail.com

1 Brunel University London, London, UK 